\title{
Inclusão não-homofóbica: um diálogo entre estudantes de medicina e travestis.
}

\section{Non-homophobic inclusion: a dialogue between medicine students and transvestites.}

Valéria Ferreira Romano*

\begin{abstract}
Resumo
Trabalhar habilidades de comunicação com estudantes de Medicina tem sido um desafio constante e, mais ainda, tem sido lidar com questões relacionadas ao preconceito, à homofobia, à discriminação em serviços de saúde. Desde 2001, o Programa Saúde da Família Lapa, integrante do currículo do curso de Medicina da UNESA, tem enfrentado esse desafio, promovendo o encontro entre os estudantes e os travestis, a partir do foco na visita domiciliar, atividades de educação em saúde e atendimento ambulatorial. O objetivo é refletir sobre as habilidades de comunicação de estudantes de Medicina, a partir da inclusão dos travestis em serviços de Atenção Básica freqüentados por estes estudantes. Como metodologia, foram adotados: registro de observação direta; entrevistas com perguntas abertas com estudantes e travestis de uma área adscrita. Como resultado, tivemos melhor desempenho na comunicação dos estudantes diante de situações relacionadas à homofobia e ao acesso dos travestis aos serviços de saúde, garantindo integralidade, eqüidade e universalidade ao SUS de todos nós. Tanto os estudantes quanto os travestis desejam uma aproximação que estimule um encontro humanizado e inclusivo, colocando em questão velhos preconceitos valorizando formas de atendimento na sintonia do acolhimento.
\end{abstract}

\begin{abstract}
Introduction: Teaching communication skills to medical students is a constant challenge, mainly when it comes to issues such as prejudice, homophobia and discrimination in the health services. Since 2001, the Family Health Program Lapa, part of the curriculum of the medical course of UNESA, has faced this challenge by promoting a dialogue between medical students and transvestites in the course household visits, bealth education activities and outpatient care. Objective: Reflect about the communication skills of medical students providing basic health care services to transvestites. Methodology: Direct observation; interviews using open questions with students and transvestites of an area covered by the program. Results: Better communication of students in situations related to homophobia and to the access of transvestites to the health services, thus contributing to the integrality, equity and universality of the Unified Health System. Conclusion: Both students and transvestites want to reach a bumanized and inclusive relationship, based on refuting old prejudice and valuing dialogue and healthcare delivery in a supportive environment.
\end{abstract}

Palavras-chave: Comunicação; Eqüidade em Saúde; Saúde da Família; Preconceito.
Key Words: Communication; Equity in Health;

Family Health; Prejudice.

*Doutora em Saúde Coletiva, Docente do Mestrado Profissional em Saúde da Família, Universidade Estácio de Sá, Rio de Janeiro, Brasil. 


\section{Introdução}

O curso de Medicina da UNESA-RJ tem como eixo curricular a Saúde da Família. Na prática, isso imprime um diálogo constante com a comunidade, especificamente quando os alunos da graduação de Medicina inauguram do nono ao décimo primeiro períodos um contato semanal com as famílias adscritas ao Programa Saúde da Família Lapa (PSF-Lapa), sob supervisão docente.

O PSF-Lapa é, portanto, parte integrante da estrutura curricular do curso de Medicina da UNESA, tendo iniciado suas atividades em 2001, a partir de um convênio firmado entre a Secretaria Municipal de Saúde do Rio de Janeiro e a Universidade.

Situado na região central do município do Rio de Janeiro, na Lapa, o PSF-Lapa pertence à Coordenação de Área Programática 1.0 e tem como referência imediata, em sua proximidade, um grande hospital de emergência, dois PAMs, uma Maternidade, além de dois hospitais especializados. A rede social no entorno é composta por igrejas católicas e evangélicas, algumas ONGs, duas escolas públicas de Ensino Fundamental e Médio, além de poucas creches. O lazer é basicamente vivenciado por meio dos inúmeros bares e casas de shows, onde se ouve de tudo: samba, forró, reagge, música eletrônica, MPB, rock, hip hop, funk, dentre outros estilos.

A comunidade adscrita é majoritariamente de adultos jovens (sem filhos) e idosos, possuindo, em média, Ensino Fundamental incompleto, com renda familiar entre dois a cinco salários mínimos, sendo o trabalho informal prevalente - são empregadas domésticas, cozinheiras, vendedores ambulantes, camelôs, caixas de supermercado, artesãos, trabalhadores da construção civil, manicuras, cabeleireiras, vigias, entregadores de panfletos, "biscateiros" etc. Muitos moram em prédios com 20 apartamentos por andar, perfazendo um espaço de três a quatro cômodos cada. Alguns vivem em prédios ocupados semi-construídos, onde a população vive com ligação ilegal de luz, sem segurança interna, sem elevadores (para subir até mesmo ao $12^{\circ}$ andar).

Existem inúmeros casarões centenários na região, chamados também de cortiços, originalmente construídos pelos patrões para alojar seus empregados. Dentro desses cortiços (a maioria em estado precário de conservação), moram várias famílias dividindo o mesmo espaço entre si. Lá, os banheiros são coletivos, assim como as cozinhas, as salas e varais. Os moradores são expostos a corte de luz, ameaça de despejo, exploração de pessoas que se autodenominam donas do local - cobrando taxas, muitas vezes, irregulares -, além de conviverem com baratas, ratos, sujeira e pobreza.

Os travestis do território delimitado moram principalmente nesses cortiços.

As atividades do PSF-Lapa englobam: atendimento ambulatorial, atividades de educação em saúde e visitas domiciliares. Isso não difere das esperadas pelo modelo de atenção da integralidade; no entanto, algumas adaptações mereceram destaque no trabalho específico com os travestis.

\section{Com os travestis é diferente?}

Optamos por utilizar visitas domiciliares semanais, já que os travestis pouco freqüentavam, espontaneamente, o ambulatório do PSF-Lapa, apesar de possuírem algumas doenças já instaladas e muitos problemas a serem enfrentados.

Começamos a manter uma sistemática de visitas domiciliares: chegávamos sempre no final da tarde, quando eles estavam começando a acordar, já que trabalhavam a noite inteira na prostituição. Levávamos camisinha, gel lubrificante, aparelho de pressão, papéis de encaminhamento, receituário, alguns remédios e, mais do que tudo: disposição em escutar, paciência, bom humor e tempo. Tempo para ouvir suas histórias, desarmar suas defesas, compartilhar seu sofrimento, nada diferente do de qualquer ser humano.

As agentes comunitárias de saúde, fundamentais na interlocução entre a equipe e a comunidade, iam aos poucos "traduzindo" as inúmeras perplexidades e os muitos abismos existentes entre o mundo médico oriundo da Academia, repleto de teorias, e a vida que eles levavam na 
lógica das ruas.

Inúmeras vezes, repeti para os alunos: "Chamemnas pelo artigo feminino", "Perguntem como desejam ser chamadas", "Escrevam no prontuário o nome do registro de nascimento, mas coloquem entre parênteses o nome feminino".

Aos poucos, fomos conquistando um espaço, fazendo diferença. Conseguimos resolver muitas situações pendentes, realizamos vários diagnósticos de HIV, marcação de consultas para especialistas, para fisioterapia, para odontologia, para fonoaudiologia. Tratamos diversas patologias: dermatológicas, AIDS, DSTs, hepatites, toxoplasmose, pneumonia, tuberculose, fissuras anais, ansiedade, problemas psiquiátricos. Assim, como no território do PSFLapa residem cerca de 50 travestis, podemos afirmar que todos são acompanhados pelos alunos e pela equipe.

\section{E os alunos nisto?}

Os estudantes de Medicina, principalmente do gênero masculino, de início, mantinham uma postura reativa, e não queriam atender os travestis. Percebendo que esta comunicação era inevitável e que não poderia estar pautada por preconceito, intolerância e exclusão, decidimos problematizar com eles a existência de uma questão a ser resolvida: Como lidar com uma população adscrita que tinha suas necessidades de saúde definidas? Como negar atendimento diante da Constituição que preconiza a saúde como direito de todos e dever do Estado? Como seria possível tornar-se um médico virando o rosto para a universalidade, a integralidade e a equidade? Dar um passo a trás do SUS? Fechar em um discurso intolerante? Manter a exclusão social dos travestis?

Os alunos são, em sua maioria, de classe média, pagantes de uma Universidade privada e criados em um ambiente protegido. Muitos sequer conheciam o centro da cidade, mesmo tendo sido nascidos e criados no Rio de Janeiro. Era natural o estranhamento de uma realidade social tão diversa da deles. Mas estavam ali se preparando para se tornarem jovens médicos; e eu, enquanto educadora, procurava mobilizar neles o que possuíam de mais instigante: a curiosidade, o despojamento, o desejo de ver o mundo com os próprios olhos.

\section{A Biomedicina e a formação médica}

Seria desejável que, de fato, todos os profissionais da saúde, independente de seu local de trabalho, trabalhassem na prevalência de um "compromisso e a preocupação de se fazer a melhor escuta possível das necessidades de saúde trazidas por aquela pessoa que busca o serviço" (p.116) ${ }^{1}$. Mas esta, infelizmente não é uma realidade. O que observamos são inúmeros relatos de dissabores e desencontros envolvendo os pacientes que, de uma maneira geral, procuram um hospital público ou um posto de saúde. Não que isso não ocorra no PSF, mas como aí a lógica do trabalho envolve necessariamente um vínculo efetivo entre o profissional e o usuário, esta possibilidade torna-se ainda mais indesejável. O PSF busca como saída, na oferta do vínculo entre os profissionais e os usuários, construir de fato uma relação transformadora entre ambos.

Mas, se os médicos do posto, do PSF, ou do hospital, tiveram uma formação com base na Biomedicina ou Medicina Ocidental Contemporânea na concepção de Luz ${ }^{2}$, podemos refletir que, na perspectiva da construção de mudanças na prática médica, tanto o modelo assistencial, quanto a educação médica, necessitam ser urgentemente revistas.

Indo um pouco além, a Biomedicina, entranhada na formação médica ocidental, promove a composição de um profissional, dentro de uma cultura médica, que, de maneira geral, desvaloriza o trabalho na Atenção Básica. Assim, a Biomedicina caracteriza-se por:

- pouca consideração da relação médico-paciente como elemento fundamental da terapêutica;

- busca de meios terapêuticos complexos com uso de tecnologia cara,

- pouco investimento na autonomia do paciente;

- afirmação de uma medicina que tenha como categoria central de seu paradigma a categoria de doença, e não de Saúde².

A prática do Médico de Família exige, portanto, a incorporação de valores dissonantes aos adotados pela 
Biomedicina, provocando uma contradição: como um médico formado na lógica da Biomedicina pode conciliar, negociar internamente com uma prática (Saúde da Família) que questiona seus valores de referência? E mais, como dar novo significado à lógica de atuação deste profissional e torná-lo convicto de outros valores?

A Biomedicina vincula Biologia e Medicina, legitimando "o conhecimento produzido por disciplinas científicas do campo da Biologia"3 e estruturando uma prática médica que, na tentativa de ser "científica", distancia-se do ser humano.

Muitos médicos e educadores procuram inovar e transformar saberes e práticas na direção do envolvimento do ser humano como totalidade ${ }^{4}$. Mas também a sociedade provoca novas atitudes nas instituições e, hoje, há um movimento de releitura da assistência médica que inclui a Saúde da Família na busca de uma Medicina que se aproxima de uma mudança de paradigma como a concebe $\mathrm{Luz}^{2}$.

Assim, vários Cursos de Medicina do país introduziram a Saúde da Família na Graduação ${ }^{5}$ e já contam com esta experiência, ainda que pontual e em construção, a exemplo da Universidade Estadual de Londrina, Faculdade de Medicina de Marília, Faculdade de Medicina de Ribeirão Preto (USP), Universidade Estácio de Sá (Rio de Janeiro), dentre outras.

Se considerarmos a pós-graduação em prospecção de crescimento para além das 37 instituições que mantém uma Residência em Medicina de Família e Comunidade e a condição de especialidade reconhecida pela $\mathrm{AMB}$ tendo o título de especialização como parâmetro de excelência, inferimos que, nos próximos anos, médicos mais bem preparados e com outras possibilidades na atenção ao usuário estarão influenciando uma nova geração de médicos. No entanto, teríamos um processo com resultados concretos para a mudança do paradigma médico apenas para médio e longo prazo.

Diante de um mercado de trabalho na Saúde da Família com muitas ofertas por todo o país, principalmente para o médico, e, em geral, sem exigência de qualquer qualificação prévia em Saúde da Família, o que pensar da qualidade destes muitos médicos que estão e estarão trabalhando no PSF sem um preparo devido?

Por isso a importância de refletir sobre a qualidade dos médicos de família como resposta à fundamental reestruturação do modelo de atenção à saúde, frente à expansão do PSF, em uma ótica de discussões propositivas na implementação de ações específicas frente a tantas mudanças estruturais necessárias ${ }^{6}$.

Mudanças estruturais são implementadas por "pessoas, ou sujeitos sociais, atuando nas relações que estabelecem entre si a partir do impacto que atribuem na abertura de caminho para a produção de fatos e processos" (p.13) 7 . Assim são as pessoas que, responsáveis por mudanças pretendidas, determinam, por meio de atitudes e ações, a intencionalidade de suas concepções e crenças diante de outras pessoas. São elas, portanto, que devem ser transformadas se a pretensão é de mudanças e inovações.

Posto que grande parte dos médicos que trabalham na Saúde da Família é oriunda das Escolas Públicas do país ${ }^{8}$, seja em nível de graduação ou de pós-graduação, há de se considerar as prioridades da formação médica em geral, nestas e em outras escolas, na pretensão de uma certificação futura, caracterizando o compromisso do Governo Federal junto às Instituições de ensino médico.

Mas a formação médica e as políticas públicas não se entrecruzam, muito embora estratégias para minorar este hiato tenham sido implementadas, a exemplo da instituição dos Pólos de Educação Permanente em Saúde que endereçou linhas de apoio à Saúde da Família e aos profissionais do SUS, tanto em instâncias educacionais quanto de serviços.

\section{Alguma metodologia}

A opção metodológica deste trabalho envolveu uma pesquisa qualitativa, já que o objetivo da proposta era o de descrever o observado, o discutido, o percebido. Um grau de identidade entre o sujeito e o objeto da investigação justifica antes uma situação de conforto e intimidade com o tema do que uma transgressão metodológica insuperável. 
Sendo docente, observando e entrevistando os alunos e os travestis que pertenciam ao meu círculo de convivência, freqüentemente me via surpreendida com as respostas obtidas no sentido de sua aparente independência e descolamento de uma possível influência nas mesmas, a partir do simples fato de eu estar presente. Na verdade, pesquisei com a vantagem de ser ao mesmo tempo interlocutora e expectadora do processo que se construía.

Desta maneira, o registro da observação direta e as entrevistas com questões abertas realizadas com os estudantes de Medicina e com os travestis justificaram-se na medida em que puderam sustentar e legitimar todo o trabalho em ação. Assim, Thiollent ${ }^{9}$ destaca que o que ocorre em relação ao pesquisador é uma "aparente identificação com os valores e os comportamentos que são necessários para a sua aceitação pelo grupo considerado" (p. 15) ${ }^{9}$.

A Sociologia Compreensiva como a concebe Max Weber foi nossa opção como referencial analítico, já que se contrapõe aos princípios do positivismo, que supõe do pesquisador uma neutralidade, objetividade, uma distinção entre o valor e o fato, entendendo a realidade a partir apenas daquilo que os sentidos podem perceber. Positivismo que busca estabelecer um mesmo fundamento lógico e metodológico entre as Ciências Sociais e as Ciências Naturais ${ }^{10}$.

Weber valoriza o significado da ação social, o significado das relações entre o indivíduo e a sociedade, entendendo a sociedade como "fruto de uma inter-relação de atores sociais, onde as ações de uns são reciprocamente orientadas em direção às ações dos outros" (p.51) ${ }^{10}$. Entende, assim, que as realidades sociais só podem ser apreendidas enquanto significados percebidos na interação social, não separando, em essência, as práticas, as linguagens, as coisas e os acontecimentos.

"Não existe uma análise da cultura absolutamente objetiva dos fenômenos sociais, independente dos pontos de vista especiais e parciais, segundo os quais, de forma explícita ou tática, consciente ou subconsciente, aqueles são selecionados e organizados para propósitos expositivos. Todo conhecimento da realidade cultural, como pode ser visto, é sempre conhecimento a partir de pontos de vista específicos" (p.52) ${ }^{10}$.

Como essa pesquisa pretendeu ouvir os pontos de vista específicos, enfoca questões que envolvem valores e o conhecimento tácito, entendendo que a realidade humana está imbricada e vinculada à realidade do concreto cotidiano ${ }^{11}$. Desta forma, dentro das Ciências Sociais optei pela Fenomenologia, considerada a Sociologia da vida Cotidiana por estudiosos do assunto, para embasar a construção do trabalho de campo.

A vida cotidiana pode ser entendida como estando no centro do acontecer histórico, como a verdadeira essência da substância social. E o indivíduo, como "um ser genérico, já que é produto e expressão de suas relações sociais, herdeiro e preservador do desenvolvimento humano; mas o representante do humano-genérico não é jamais um homem sozinho, mas sempre a integração" (p.21)

A vida cotidiana é a vida do ser humano inteiro, que dela participa com todos os aspectos de sua individualidade, de sua personalidade. O ser humano já nasce inserido em sua cotidianidade e torna-se maduro quando é capaz de viver por si mesmo esse dia-a-dia. Essa maturidade é assimilada a partir da manipulação das coisas envolvendo a mediação social. Assim, o ser humano estará maduro quando, a partir do que aprendeu em grupo (família, escola, comunidade), puder manter-se "autonomamente no mundo das integrações maiores, de orientar-se em situações que já não possuem a dimensão do grupo humano, comunitário, de mover-se no ambiente da sociedade em geral e, além disso, de mover por sua vez esse mesmo ambiente" (p. 19) ${ }^{12}$.

Pesquisamos, assim, a vida cotidiana dos travestis e dos estudantes de Medicina, considerando-os maduros no conceito explicitado acima.

\section{Resultados}

A partir do crescimento dos encontros com os travestis, sua estabilidade e constância, foram surgindo os primeiros resultados. Os alunos de medicina aos poucos foram concordando com o trabalho que se impunha, com 
as reivindicações legítimas dos travestis por um atendimento digno, respeitoso e igualitário.

Dessa maneira, os estudantes, surpreendentemente, começaram a mudar de postura: pediam-me para atender os travestis, perguntavam sobre suas vidas, pactuavam resolução de referências e contra-referências na preocupação de qualificar a atenção oferecida. Muitos (rapazes e moças) escolhiam minha supervisão docente porque desejavam trabalhar diretamente com os travestis.

Começamos a discutir, a debater temas inusitados para a Medicina: a homofobia, a violência contra os travestis, o uso abusivo de drogas ilícitas, a utilização muitas vezes inadequada de silicone líquido, as cirurgias para colocação de silicone nas mamas, de diminuição do diâmetro do nariz, o absenteísmo nas consultas de acompanhamento da soropositividade, a freqüente não-utilização de camisinha, apesar da farta oferta.

Assim, fomos aprimorando as competências de comunicação no desafio da educação médica, sinalizando para a importância essencial da relação médico-paciente com todas as pessoas, sem exceção.

Hoje, essa mudança de postura é a regra, exemplificada aqui por meio do relato de um egresso de nosso curso de Medicina:

"Pois é, agora que estou formado é que estou vendo o quanto aprendi a lidar com os travestis e homossexuais. Meus colegas negam atendimento, ou querem só chamar os travestis pelo nome masculino, só de implicância. Eu não, vou lá e pergunto como querem ser chamados, batalho para conseguir internação quando precisam, mostro aos colegas médicos que respeito é tudo!”.

\section{Conclusão}

Tanto os estudantes quanto os travestis realizaram um movimento de aproximação, pautado pelo esgotamento do modelo de atenção centrado na doença e na biomedicina e pela necessidade de negociação com a sociedade de maneira menos marginal e excludente.

Vários relatos dos travestis apontaram para uma indignação ao fato de serem "aceitos à noite e mal pode- rem sair de casa durante o dia", já que ficam expostos a chacotas e olhares: "[...] mesmo que esteja vestida assim, bem discreta, eles olham, eles notam que a gente é diferente, e eles só gostam disso quando chega a noite".

Os alunos de medicina dizem "Hoje eu respeito muito mais um travesti. Cada um sabe de si, se eles querem ser assim, qual é o problema?".

Em um mundo no qual a informação circula com rapidez, onde os modelos de comportamento e padrões culturais são menos monocórdios e mais fundamentados em experiências, cria-se um clima contrário à intolerância e à exclusão. As pessoas, se oportunamente estimuladas, querem dialogar, trocar saberes e superar barreiras sociais impostas.

O compromisso do docente com sua prática é, por isso, de suma importância. O docente serve de exemplo para o aluno, o qual nele se inspira na formatação de seu ideal de profissão. Um médico que sabe lidar com a competência de comunicação de maneira democrática, inclusiva, respeitosa das diferenças, trabalha a favor da construção de um SUS melhor e está maduro para influenciar positivamente toda uma geração de futuros médicos que nele se espelham.

Lidar com travestis é desafiar temas de difícil manejo para toda a área da saúde, mas, nem por isso, menos preciosos diante da realidade que se impõe: abuso de drogas lícitas e ilícitas, cirurgias estéticas de resolução ruim, violências, solidão, abandono, desconfiança, baixa auto-estima, afastamento do contato familiar, falta de acesso aos serviços de saúde, falta de acesso à medicação oferecida pelo SUS, discriminação, preconceito, exclusão social, riqueza a partir da exploração do trabalho alheio. Mas também: bom humor, alegria, busca da beleza, franqueza e solidariedade.

Não esgotando as perguntas, nem se satisfazendo com as respostas, esta pesquisa se movimenta: "Como lidar com tantas variáveis junto ao estudante de medicina?; Como imprimir neste aluno uma visão não-homofóbica na relação com o outro?; Como lidar com os preconceitos já estabelecidos e solidificados?; Um futuro profissional 
que aprende a respeitar a dignidade do outro a partir da diferença, e não da semelhança, estará melhor preparado para as surpresas da profissão?”.

A existência humana se impõe e estabelece seus sinais: somos todos iguais, sendo diferentes...

A esperança é que, mais e mais, os profissionais da saúde e a população admirem encontrarem-se na inclusão, colocando em questão velhos preconceitos para que possamos, enfim, valorizar maneiras de atendimento na sintonia do acolhimento, no compromisso com o cuidado e no respeito à vida.

\section{Referências}

1.Cecílio LCO. As Necessidades de Saúde como conceito estruturante na luta pela integralidade e equidade na atenção à saúde. In: Mattos RA, Pinheiro R. org. Os Sentidos da Integralidade na atenção e no cuidado à saúde. Rio de Janeiro: UERJ, IMS: ABRASCO; 2001.

2.Luz MT. Cultura Contemporânea e Medicinas Alternativas: Novos Paradigmas em Saúde no Fim do Século XX. Physis: revista de saúde coletiva 1997; (7): 1.

3.Camargo KRJ. A Biomedicina. Physis: revista de saúde coletiva 1997; 7(1).

4.Perestrelo D. A Medicina da Pessoa. 3 ed. Rio de Janeiro, São Paulo: ATHENEU; 1982.

5.Feuerwerker L. Além do Discurso de Mudança na Educação Médica Processos e Resultados. São Paulo; Londrina; Rio de Janeiro: HUCITEC; Rede UNIDA; Associação Brasileira de Educação Médica; 2002.

6.Romano VF. Certificação por Competência para o Médico de Família: uma proposta em construção. [Tese] Rio de Janeiro, UERJ. Instituto de Medicina Social, 2006.

7.Almeida MJ. Educação Médica e Saúde - possibilidades de mudança. Londrina; Rio de Janeiro: UEL, Associação Brasileira de Educação Médica; 1999.

8.Machado MH; SOUZA HM.; SOUSA MF. Perfil dos Médicos e Enfermeiros do Programa Saúde da Família no Brasil - relatório final. Brasília (DF): FIOCRUZ, Ministério da Saúde: Departamento Atenção Básica / Secretaria de Políticas de Saúde; 2000.
9.Thiollent M. Metodologia da Pesquisa-ação. 10 ed. São Paulo: Cortez. Autores Associados, 2000. Thiolent M. Metodologia da Pesquisa-ação. 10 ed. São Paulo: Cortez. Autores Associados; 2000.

10.Minayo MCS. O desafio do conhecimento: pesquisa qualitativa em saúde. 8 ed. São Paulo: HUCITEC; 2004. 11.Tedesco JC. Paradigmas do cotidiano: introdução à constituição de um campo de análise social. Santa Cruz do Sul: EDUNISC; 1999.

12.Heller A. O Cotidiano e a História. 6 ed. São Paulo: Paz e Terra; 2000.

\section{Endereço para correspondência:}

Rua Assis Brasil 70/1002 - Copacabana

Rio de Janeiro, RJ.

CEP: 22230-010

\section{Endereço eletrônico:}

valromano@uol.com.br 